ISSN Print : 1411 -951 X, ISSN Online : 20503-1716

Jurnal Ergonomi Indonesia

(The Indonesian Journal of Ergonomic)

Vol.3, No.2 : 1 Juli-Desember 2017

\title{
Postur Kerja dan Risiko Low Back Pain pada Pekerja Pasiran
}

\author{
Denny Nurkertamanda ${ }^{a, b, *}$, I Nyoman Adiputra ${ }^{c}$, Ketut Tirtayasa ${ }^{c}$, I Putu Gede Adiatmika ${ }^{c}$. \\ ${ }^{a}$ Pascasarjana Ilmu Kedokteran, Fakultas Kedokteran Universitas Udayana, Bali \\ ${ }^{\mathrm{b}}$ Departemen Teknik Industri, Universitas Diponegoro, Semarang Jawa Tengah \\ ${ }^{\mathrm{c}}$ Bagian Ilmu Faal, Fakultas Kedokteran, Universitas Udayana, Bali
}

\begin{abstract}
Abstrak
Salah satu pekerjaan angkat angkut adalah pekerjaan menurunkan pasir dari atas truk. Dalam bekerja pekerja menggunakan alat bantu berupa enggrong yang merupakan sekop dengan bergagang pendek. Akibat penggunaan enggrong pekerja bekerja dengan postur tubuh membungkuk. Postur kerja ini menimbulkan potensi low back pain pada pekerja. Penelitian ini merupakan penelitian cross sectional dengan jumlah sampel 9 partisipan. Tujuan dari penelitian adalah untuk mengetahui potensi risiko low back pain berdasarkan sudut kemiringan trunk ketika pekerja bekerja menurunkan pasir dengan enggrong. Sudut kemiringan trunk yang diprediksi meliputi: 1) sudut kemiringan trunk flexion, 2) sudut kemiringan trunk bending, dan 3) sudut kemiringan trunk twisting. Data postur kerja diambil dengan menggunakan kamera 3D Microsoft Kinect ${ }^{\mathrm{TM}}$ dan dianalisis dengan menggunakan software Siemen Jack metode 3D Static Strength Prediction Program (3DSSPP) untuk memprediksi sudut kemiringan trunk. Hasil analisis dari ke-6 postur kerja menunjukkan postur-postur kerja yang sering dilakukan pekerja mempunyai rerata sudut kemiringan trunk flexion sebesar $61,1^{0} \pm 10,09^{0}$, sudut kemiringan trunk bending sebesar $19,8^{0} \pm 6,74^{0}$ dan sudut kemiringan trunk twisting sebesar $20,0^{\circ} \pm 9,03^{\circ}$. Rerata sudut kemiringan trunk flexion yang mencapai $87,28 \%$ dari sudut kemiringan maksimal merupakan penyebab utama risiko low back pain. Sehingga dapat disimpulkan potensi terjadinya low back pain pada pekerja pasiran dapat terjadi. Perlu intervensi ergonomi untuk mencegah dan mengurangi potensi risiko terjadi low back pain pada pekerja pasiran.
\end{abstract}

Kata kunci: low back pain, manual angkat angkut, sudut kemiringan trunk, 3DSSPP

* E-mail address: nurkerta@gmail.com (Denny Nurkertamanda) 
ISSN Print : 1411 - $951 \mathrm{X}$, ISSN Online : 20503-1716

Jurnal Ergonomi Indonesia

(The Indonesian Journal of Ergonomic)

Vol.3, No.2 : 1 Juli-Desember 2017

\begin{abstract}
One of the manual matrial handling jobs is the derivative work from the top of the truck. In working the workers use a tool that enggrong which is a short-handed shovel. Due to the use of employee enggrong work with stooped posture. This work posture raises the potential for low back pain in workers. This study is a cross sectional study with a sample of 9 participants. The purpose of research is to find potential risks of low back pain based on angle trunk when workers work sent down the sand by enggrong. Angle trunk which is predicted covering: 1 angle trunk flexion, 2) angle trunk bending, and 3) angle trunk twisting. Work posture data was taken using Microsoft Kinect ${ }^{T M} 3 D$ camera and analyzed by using Siemen Jack 3D Static Strength Prediction Program (3DSSPP) software to predict angle trunk. The result of the analysis of the 6 work postures showed that worker's frequently employed posture had the average angle trunk flexion of $61.1^{0} \pm 10.09^{\circ}$, angle trunk bending of $19.8^{\circ} \pm 6.74^{\circ}$ and angle trunk twisting of $20.0^{\circ} \pm 9.03^{\circ}$. The average angle trunk flexion at $87.28 \%$ of maximal angle is a major cause risk low back pain. So that it can be summed up the potential for low back pain on sand workers. Intervention ergonomics need to prevent and reduce potential risks happened low back pain on sand workers.
\end{abstract}

Keywords: manual material handling, low back pain, angle trunk, 3DSSP 
ISSN Print : 1411 -951 X, ISSN Online : 20503-1716

Jurnal Ergonomi Indonesia

(The Indonesian Journal of Ergonomic)

\section{Pendahuluan}

Pekerja pasiran adalah pekerja yang bertugas menurunkan pasir dari atas truk. Dalam bekerja, pekerja pasiran menggunakan skop bergagang pendek dengan sebutan enggrong. Penggunaan enggrong tersebar luas di wilayah Jawa Tengah dan Yogyakarta. Selama proses penurunan pasir berlangsung, pekerja bekerja dengan postur tubuh membungkuk. Sistem kerja pekerja pasiran termasuk dalam pekerjaan angkat angkut (manual material handling) (Karwowski \& Rodrick dalam Salvendy, 2001) dengan tingkat risiko penyakit akibat kerja yang tinggi (Karwowski \& Rodrick dalam Salvendy, 2001; Petersson et al. dalam Zandin, 2004) dan kecelakaan kerja (Bloswick \& Sesek dalam Zandin, 2004; Manuaba, 1998; Sutjana, 2014). Berbagai bentuk penyakit akibat kerja terjadi pada bagian-bagian tubuh tertentu seperti: musculoskeletal disorders (MSDs), back pain disorders (BPDs) (Salvendy, 2001; Zandin, 2004; Violante et al., 2003), repentitive strain injuries (RSIs), repetitive motion injuries (RMI), dan cumulative trauma disorders (CTD) (Gilad dalam Zandin, 2004), menyebabkan keluhan sakit/ nyeri dan dapat juga berakibat kehilangan kemampuan untuk bekerja (Violante et al., 2003).

Pekerjaan angkat angkut adalah pekerjaan yang berisiko terhadap kesehatan dan keselamatan pekerja, kesalahan tata cara kerja dalam proses angkat angkut akan mengakibatkan dampak kesehatan dalam jangka pendek maupun jangka panjang.

Penggunaan alat bantu enggrong ketika bekerja menurunkan pasir, menyebabkan pekerja bekerja dengan postur tubuh membungkuk, hal ini dilakukan karena gagang enggong yang relatif pendek. Selama
Vol.3, No.2 : 1 Juli-Desember 2017

proses penurunan pasir berlangsung, pekerja bekerja dengan postur tubuh membungkuk.

Postur kerja membungkuk sangat berisiko memimbulkan potensi low back pain. Penelitian Bridger (1998) memperlihatkan pada postur pekerja mengali tanah dengan sekop memimbulkan potensi terjadinya low back pain. Penelitian Davis dan Anes (2014) menunjukkan sudut kemiringan trunk ketika bekerja dapat meningkatkan potensi terjadinya low back pain.

Penelitian ini berfokus pada sudut kemiringan trunk pada saat pekerja pasiran bekerja menurunkan pasir dari atas truk menggunakan alat bantu enggrong dan korelasinya dengan low back pain.

\section{Materi dan Metode}

\subsection{Subjek}

Subjek terdiri dari 9 orang pekerja pasiran dengan status kesehatan sehat dan tanpa cacat tubuh. Umur rata-rata subjek (standar deviasi) 42,22 \pm 8,43 tahun dengan pengalaman kerja $11,11 \pm 3,51$ tahun dan indeks massa tubuh $22,59 \pm 09 \mathrm{~kg} / \mathrm{m}^{2}$.

\subsection{Desain eksperimen}

Penelitian ini merupakan penelitian cross sectional dengan jumlah sampel 9 partisipan. Pekerja bekerja dengan pola kerja seperti biasanya tanpa adanya intervesi bentuk pola kerja, bekerja menggunakan enggrong standar yang biasa digunakan oleh pekerja pasiran (Gambar 1). Setiap sampel akan bekerja dengan menggunakan enggrong untuk menurunkan muatan pasir sebanyak $5,5 \mathrm{~m}^{3}$ pasir dari atas truk dengan waktu yang tidak dibatasi. 
ISSN Print : 1411 -951 X, ISSN Online : 20503-1716

Jurnal Ergonomi Indonesia

(The Indonesian Journal of Ergonomic)

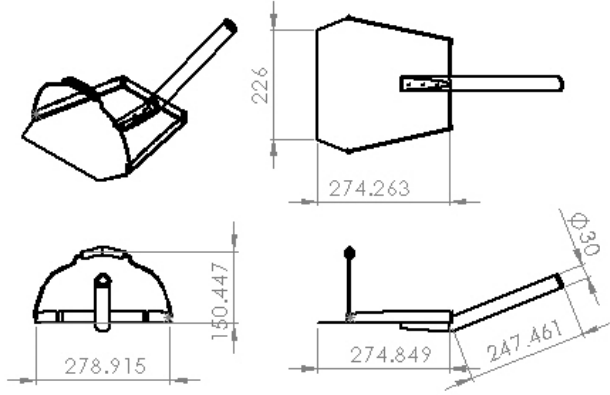

Gambar 1. Spesifikasi enggrong

\subsection{Pengambilan data dan analisis}

Pengambilan data postur tubuh pekerja dilakukan saat pekerja bekerja. Selama bekerja postur tubuh pekerja di rekam dengan kamera 3D Microsoft Kinect $^{\mathrm{TM}}$ V1 (Xu dan McGorry, 2015), citra postur tubuh pekerja diolah dan ditampilkan perangkat lunak Siemen Jack. Sudut kemiringan trunk diprediksi dengan perangkat lunak 3D Static Strength Prediction Program / 3DSSPP (Rajaee et al., 2015). Postur-postur tubuh pekerja yang dianalisis adalah postur-postur dalam satu siklus gerakan dan postur yang sering dilakukan oleh pekerja

\section{Hasil dan Pembahasan}

\subsection{Hasil}

Siklus gerakan yang sering dilakukan pekerja adalah siklus gerakan yang mengayunkan pasir ke arah samping dengan postur kerja yang dianalisis adalah 6 postur pekerja (Gambar 2).

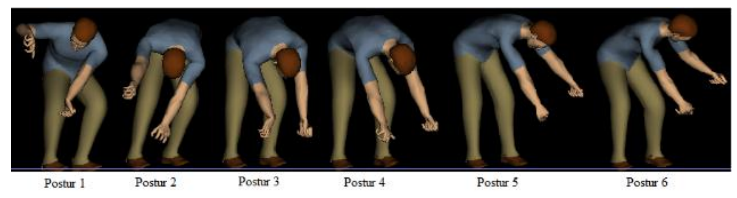

Gambar 2. Postur-postur pekerja

Hasil olah data dengan menggunakan perangkat lunak Siemen Jack metode prediksi 3DSSPP diperoleh rerata untuk ke6 postur adalah sudut kemiringan trunk
Vol.3, No.2 : 1 Juli-Desember 2017

flexion sebesar $61,1^{0} \pm 10,09^{0}$, sudut kemiringan trunk bending sebesar $19,8^{0} \pm$ $6,74^{0}$ dan sudut kemiringan trunk twisting sebesar $20,0^{\circ} \pm 9,03^{\circ}$. Kemiringan sudut trunk flexion tertinggi $71,1^{0}$ dan terendah $49,1^{0}$ dengan tiga postur kerja (Postur No. 2, 3 dan No. 4) menunjukkan kemiringan sudut mencapai sudut kemiringan maksimum (Gambar 3). Sudut kemiringan trunk bending bernilai negatif berarti trunk bending ke arah kanan, sedangkan bernilai positif berarti trunk bending ke arah kiri. Sudut kemiringan trunk bending terbesar adalah sudut kemiringan trunk bending pada Postur No. 1 sebesar $-31,4^{0}$ dan terendah pada Postur No. 4 sebesar $11,5^{0}$ (Gambar 4 ). Sudut kemiringan trunk bending pada Postur No.1 telah melampaui sudut kemiringan trunk bending maksimal yang dapat dilakukan. Sudut kemiringan trunk twisting bernilai positif berarti sudut kemiringan trunk twisting searah jarum jam dan bernilai negatif jika berlawanan arah putar jarum jam. Sudut kemiringan trunk twisting terbesar adalah sudut kemiringan trunk twisting pada Postur No. 2, sebesar 30,7 (Gambar 5). Sudut kemiringan trunk twisting Postur No.2 masih berada di bawah sudut kemiringan trunk twisting maksimum.

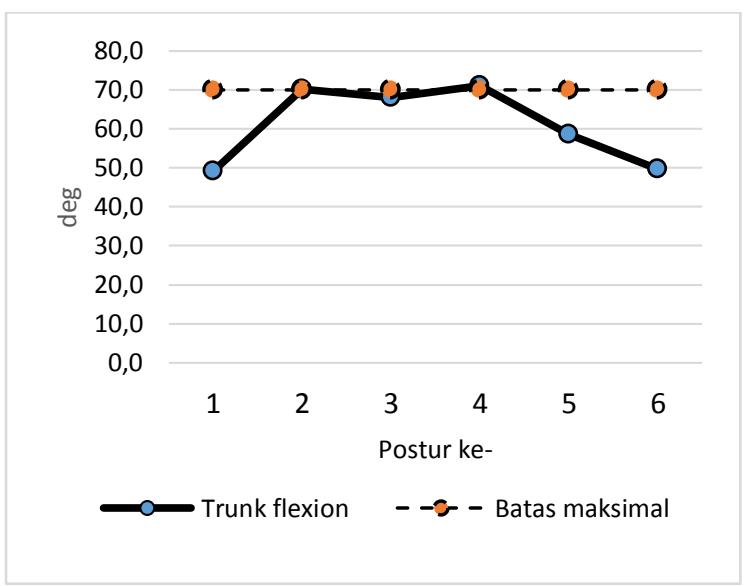

Gambar 3. Sudut kemiringan trunk flexion 
ISSN Print : 1411 -951 X, ISSN Online : 20503-1716

Jurnal Ergonomi Indonesia

(The Indonesian Journal of Ergonomic)

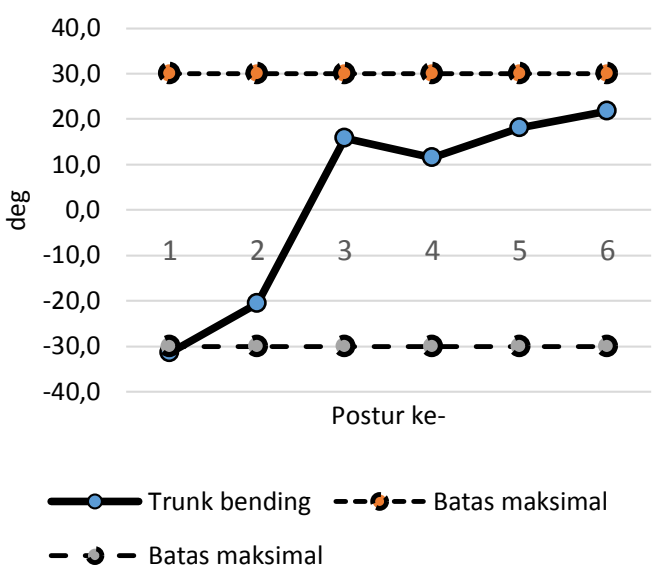

Gambar 4. Sudut kemiringan trunk bending

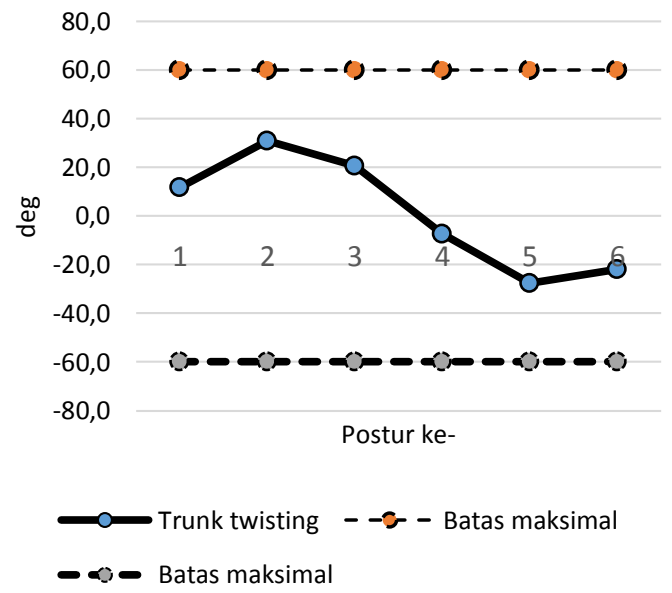

Gambar 5. Sudut kemiringan trunk twisting

\subsection{Pembahasan}

Sudut kemiringan trunk meliputi sudut kemiringan trunk flexion, sudut kemiringan trunk bending dan sudut kemiringan trunk twisting. Sampai saat ini belum ada konsensus atau batasan yang disepakati untuk sudut kemiringan trunk yang aman dalam bekerja. Dari beberapa penelitian besaran sudut kemiringan trunk adalah sudut kemiringan trunk maksimum yang dapat dilakukan oleh tubuh manusia. Penelitian Pearcy et al. (1998) dalam Delleman et al. (2004) menyatkan bahwa sudut kemiringan maksimum yang bisa dicapai sebesar $70^{\circ}$. Penelitian McGill et al. (1999) dalam
Vol.3, No.2 : 1 Juli-Desember 2017

Delleman et al. (2004), menyatakan bahwa sudut kemiringan trunk bending maksimum sebesar $30^{\circ}$ ke arah kanan dan kiri. Serta penelitian Boden \& Oberg (1998) dalam Delleman et al. (2004), menyatakan bahwa sudut kemiringan trunk twisting maksimal yang dapat dicapai sebesar $60^{\circ}$ dengan arah putar serah atau berlawanan arah jarum jam.

Dari hasil analisis diperoleh rerata sudut kemiringan trunk flexion mencapai 87,28 \% dari sudut kemiringan trunk flexion maksimal. Sudut kemiringan trunk flexion ini hampir mencapai batasan maksimal, bahkan ada 3 postur kerja yang mencapai dan melewati batasan maksimal. Rerata sudut kemiringan trunk bending mencapai $66,00 \%$ dari sudut kemiringan trunk bending maksimal. Sudut kemiringan trunk bending hanya ada satu postur kerja yang mencapai sudut kemiringan maksimal yaitu pada Postur No. 1. Rerata angle trunk twisting pada mencapai 33,33\% dari sudut kemiringan trunk twisting maksimal. Sudut kemiringan trunk twisting tidak ada yang melwati batasan maksimal yang dapat dilakukan oleh tubuh.

Makin besar sudut kemiringan gaya, maka makin besar juga tekanan gaya pada low back disc. Besarnya tekanan gaya pada low back disc akan meningkatkan potensi terjadi low back pain (Kumar, 1999; Bridger, 2005; Marras \& Karwowski, 2006; Karwowski, 2006) Salah satu potensi terjadi low back pain adalah seringnya postur tubuh dalam posisi tidak netral membungkuk ke depan (Norman et al. (1991) dalam Delleman et al., 2004). Penelitian menunjukkan bahwa bekerja dengan posisi membungkuk ke depan (sudut kemiringan trunk flexion) dengan sudut $>60^{\circ}$ selama $5 \%$ dari total waktu kerja meningkatkan risiko terjadinya low back pain sebanyak $50 \%$ dan jika terjadi ada sudut kemiringan trunk 
ISSN Print : 1411 -951 X, ISSN Online : 20503-1716

\section{Jurnal Ergonomi Indonesia}

(The Indonesian Journal of Ergonomic)

twisting selama $10 \%$ dari total waktu kerja meningkatkan low back pain sebanyak 30\% (Hoogendoorn et al. (2000) dalam Delleman et al., 2004). Penelitian lain menyebutkan bahwa pekerja dengan postur tubuh posisi sudut kemiringan trunk bending lebih besar $20^{\circ}$ selama $10 \%$ dari total waktu kerja meningkatkan risiko terjadi low back pain (David et al, 2008). Penelitian pada pekerja paramedik menunjukkan bekerja dengan sudut kemiringan trunk flexion $>40^{\circ}$ dan sudut kemiringan trunk twisting > $24^{0}$ selama $21 \%$ dan $17 \%$ total waktu kerja akan meningkatkan risiko terjadi low back pain (Prairie \& Corbeil, 2014).

Berdasarkan penelitian - penelitian sebelumnya terlihat bahwa sudut kemiringan trunk flexion lebih besar dari $60^{\circ}$ untuk durasi waktu $5 \%$ dari total waktu kerja dapat meningkatkan risiko low back pain sebanyak 50\%. Untuk sudut kemiringan trunk bending $>20^{\circ}$ selama durasi waktu 10 $\%$ dari total waktu kerja dapat meningkatkan low back pain. Demikian juga untuk sudut kemiringan trunk twisting, > $24^{0}$ dapat meningkatkan potensi low back pain. Postur kerja pekerja pasiran merupakan postur kerja dengan kondisi trunk pada tiga kombinasi sudut kemiringan. Sehingga kombinasi sudut kemiringan trunk flexion, bending dan twisting terjadi dalam setiap postur kerja.

Hal ini berarti potensi terjadinya low back pain pada pekerja pasiran yang bekerja menggunakan enggrong akan terjadi. Sudut kemiringan trunk flexion menyumbang potensi terbesar terjadinya low back pain, karena rerata sudut kemiringan trunk flexion $61,1^{0} \pm 10,09^{\circ}$ dan tiga dari 6 postur kerja telah mencapai sudut kemiringan maksimum.

Selain potensi terjadinya low back pain, postur kerja yang membungkuk juga
Vol.3, No.2 : 1 Juli-Desember 2017

berpotensi terjadinya kelelahan otot skeletal (musculoskeletal disorders) dan meningkatkan beban kerja pekerja.

\section{Simpulan dan Saran}

Analisis postur tubuh dengan sudut kemiringan trunk pada postur pekerja pasiran menunjukkan adanya potensi risiko low back pain, sehingga sangat diperlukan intervensi ergonomi untuk memperbaiki kondisi kerja pekerja pasiran. Intervensi ergonomi diharapkan mampu mengurangi potensi low back pain, keluhan otot skeletal (musculoskeletal disorders) dan beban kerja.

\section{Daftar Pustaka}

Bridger, R. S. 2005. Introduction to Ergonomics, Instructor's Manual. Taylor \& Francis e-Library.

Bridger, R. S., Sparto, Patrick., Marras, William S. 1998. Spade Design, Lumbar Motions, Riskof Low-Back Injury and Digging Posture. Occupational Ergonomics. 1(3), 157-172.

David, G., Woods, V., Vi, G., Bukle,P. 2008. The Development of the Quick Exposure Checklist (QEC) for Assessing Exposure Risk Factors for Work-related Musculoskeletal Disorders. Applied Ergonomics. 39, 57-69.

Davis, Kermit G., Anes, Lida Orta. 2014. Potential of Adjustable Height Cart in Reducing the Risk of Low Back Injury in Gosery Stockers. Applied Ergonomics. 45, 285-292.

Delleman, Nico J., Haslegrave Christine M., Chaffin, Don B. 2004. Working Postures and Movements, Tools for Evaluation and Engineering. CRC Press LLC.

Karwowski, Waldemar. 2006. International Encyclopedia of Ergonomics and Human Factors. Taylor \& Francis Group.

Kumar, Shrawan. 1999. Biomechanic in Ergonomics. Taylor \& Francis, Inc. 
ISSN Print : 1411 -951 X, ISSN Online : 20503-1716

Jurnal Ergonomi Indonesia

(The Indonesian Journal of Ergonomic)

Manuaba, Adnyana. 1998. Dengan Desain Yang Aman Mencegah Kecelakaan Dan Cidera. in Bunga Rampai Ergonomi Vol I. Program Pascasarjana Universitas Udayana.

Marras, William S. and Karwowski, Waldemar. 2006. Fundamentals and Assessment Tools for Occupational Ergonomics. Second Edi. CRC Pres, Francis \& Taylor Group.

Prairie, Jerome., Corbeil, Philippe. 2014. Paramedics on the Job: Dynamic Trunk Motion Assessement at the Workplace. International Journal of Industrial Ergonomics. 45, 895-903.

Rajaee, Mohammad Ali., Arjmand, Navid., Shirazi-Adl, Aboulfazl., Plamondon, Andre., Schmidt, Hendrik. 2015. Comparative evaluation of six quantitative lifting tolls to estimate spine loads during static activities. Applied Ergonomics. 48, 22-32.

Salvendy, Gavriel. 2001. Handbook of Industrial Engineering, Technology and Operations Management. Thrid Edi. John Wiley \& Sons, Inc.

Sutjana, I. D. P. 2014. Penyakit Akibat Kerja. in Kumpulan Makalah Ergonomi, Jilid1. Program Pascasarjana Universitas Udayana.

Violante, Francesco., Armstrong, Thomas., Kilbon, Asa. 2003. Occupational Ergonomics: Work Related Musculoskeletal Disorders of the Upper Limb and Back. Taylor \& Francis eLibrary.

$\mathrm{Xu}, \mathrm{Xu}$., McGorry, Reymond W. 2015. The Validity of the first and second generation Microsoft Kinect $^{\mathrm{TM}}$ for identifying joint center location during static postures. Applied Ergonomics. 29, 47-54.

Zandin, Kjell B. 2004. Maynard'S Industrial Engineering Handbook. Fifth Edit. Mcgraw-Hill Standard Handbook. 